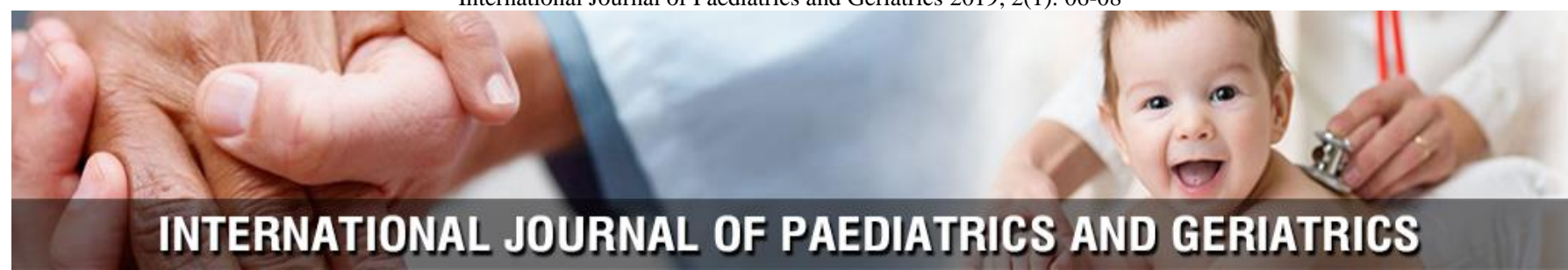

P-ISSN: 2664-3685

E-ISSN: $2664-3693$

www.paediatricjournal.com

IJPG 2019; 2(1): 06-08

Received: 11-11-2018

Accepted: 14-12-2018

Dr. Aman Sharma

Department of Paediatrics,

Lady Hardinge Medical

College, New Delhi, India

\section{Determination cases of bacterial meningitis in children: A clinical study}

\section{Dr. Aman Sharma}

DOI: https://doi.org/10.33545/26643685.2019.v2.i1a.19

\begin{abstract}
Background: Bacterial meningitis is a severe, life-threatening infection of the central nervous system common in children. The present study was conducted to determine cases of bacterial meningitis in children.

Materials \& Methods: The present study was conducted in the department of Pediatrics on 45 children age ranged 1 year to 12 years of both genders. Parents were informed regarding the study. Diagnosis of bacterial meningitis was made based on the clinical picture and positive CSF culture and CSF leukocytosis.

Results: Age group 1-4 years had 9 boys and 14 girls, 5-8 years had 7 boys and 6 girls and 8-12 years had 4 boys and 5 girls. Common findings were fever in 42, vomiting in 36, rashes in 34, drowsiness in 32 , headache in 20 , convulsions in 8 , nuchal rigidity in 5 and diarrhea in 12 . The difference was significant $(P<0.05)$. Causative organisms were Streptococcus pneumonia in 25 cases, Haemophilus influenza type $\mathrm{b}$ in 12 and Neisseria Meningitidesin 8 patients. The difference was significant $(P<$ $0.05)$.
\end{abstract}

Conclusion: The most common causative organisms was Streptococcus pneumonia. There were 45 cases of bacterial meningitis.

Keywords: bacterial meningitis, Haemophilus influenza, Streptococcus pneumonia

\section{Introduction}

Bacterial meningitis is a severe, life-threatening infection of the central nervous system that requires immediate medical attention ${ }^{[1]}$. Even with appropriate treatment, morbidity and mortality can be substantial. Bacterial meningitis is a life threatening infection caused by bacterial invasion of the meninges and its incidence and mortality rates are much higher in the third world countries. Between $10-20 \%$ of those who survive bacterial meningitis suffer permanent damage. Diagnosis may be difficult as clinical features are often nonspecific, especially in young children. There are three common etiologic organisms namely, Haemophilus influenza type B, Streptococcus pneumonia and Meningococcal meningitides depending on age, sex, race, season and immunologic status of the child. Cerebrospinal fluid (CSF) is very helpful in diagnosis ${ }^{[2]}$.

In infants and young children worldwide, Streptococcus pneumoniae, Neisseria meningitides, and Haemophilus influenzae type b (Hib) are the most common causes of bacterial meningitis. Among children older than 5 years of age and adolescents, $\mathrm{S}$. pneumoniae and $\mathrm{N}$. meningitidis are the predominant causes of bacterial meningitis ${ }^{[3]}$.

Factors that increase the risk for bacterial meningitis include immunosuppressive states, such as HIV infection, asplenia, terminal complement deficiencies, and immunoglobulin deficiencies. Penetrating head injuries, neurosurgical procedures, or the presence of cerebrospinal fluid (CSF) leaks are other risk factors for meningitis. Patients with ventriculoperitoneal shunts are at risk of meningitis caused by staphylococci (especially coagulase-negative strains) and gram-negative organisms, including Pseudomonas ${ }^{[4]}$. The present study was conducted to determine cases of bacterial meningitis in children.

\section{Materials \& Methods}

The present study was conducted in the department of Pediatrics. It consisted of 45 children age ranged 1 year to 12 years of both genders. Parents were informed regarding the study. Ethical approval was obtained from institute prior to the study.

General information such as name, age, gender etc. was recorded. Diagnosis bacterial meningitis was made based on the clinical picture and positive CSF culture and CSF leukocytosis.
Corresponding Author: Dr. Aman Sharma Department of Paediatrics, Lady Hardinge Medical College, New Delhi, India 
Results thus obtained were subjected to statistical analysis. $P$ value less than 0.05 was considered significant.

\section{Results}

Table 1: Age wise distribution of patients

\begin{tabular}{|c|c|c|}
\hline Age group (Years) & Boys & Girls \\
\hline $1-4$ & 9 & 14 \\
\hline $5-8$ & 7 & 6 \\
\hline $8-12$ & 4 & 5 \\
\hline Total & 20 & 25 \\
\hline
\end{tabular}

Table I shows that age group 1-4 years had 9 boys and 14 girls, 5-8 years had 7 boys and 6 girls and 8-12 years had 4 boys and 5 girls.

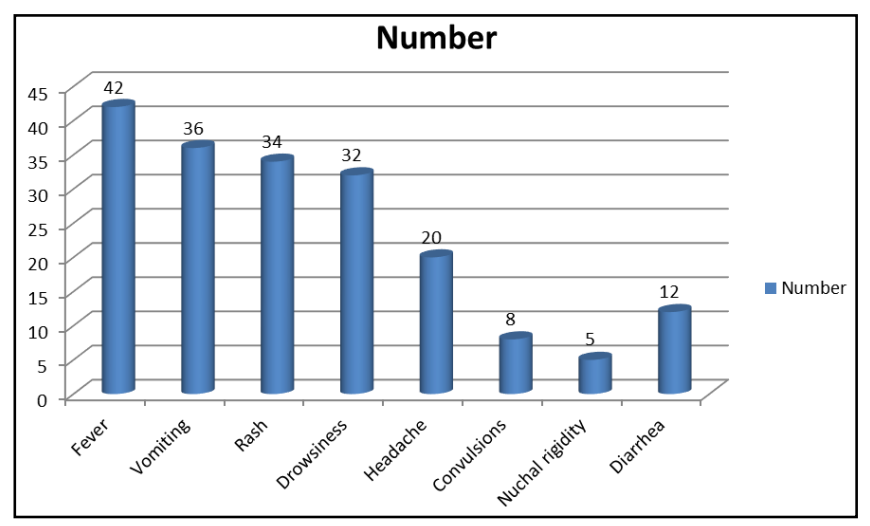

Graph I shows that common findings were fever in 42, vomiting in 36 , rashes in 34 , drowsiness in 32 , headache in 20 , convulsions in 8 , nuchal rigidity in 5 and diarrhea in 12 . The difference was significant $(\mathrm{P}<0.05)$.

Graph 1: Clinical features in patients

Table 2: Type of causative organisms detected by CSF culture

\begin{tabular}{|c|c|c|}
\hline Causative organisms & Number & P value \\
\hline Streptococcus pneumoniae & 25 & \multirow{2}{*}{0.01} \\
\cline { 1 - 2 } Haemophilus influenza type b & 12 & \multirow{2}{*}{0.0} \\
\cline { 1 - 2 } Neisseria Meningitides & 8 & \\
\hline
\end{tabular}

Table III shows that causative organisms were Streptococcus pneumoniae in 25 cases, Haemophilus influenza type b in 12 and Neisseria Meningitides in 8 patients. The difference was significant $(\mathrm{P}<0.05)$.

\section{Discussion}

Acute bacterial meningitis has a relatively rapid onset of symptoms, and routine laboratory techniques can usually identify the pathogen. ${ }^{5}$ The most common causes have been Streptococcus pneumoniae, Neisseria meningitidis, Haemophilus influenzae type $b$ (Hib), group B Streptococcus (GBS), and Listeria monocytogenes. These organisms caused more than $80 \%$ of acute bacterial meningitis in children during the 1970s and 1980s. In 1990, conjugate Hib vaccine was introduced [6]. It has almost eliminated Hib meningitis in countries. In developed countries, conjugated vaccines have decreased the incidence of bacterial meningitis in all age groups except children younger than 2 months. The success of the vaccines has shifted the median age of meningitis disease from younger than 5 years of age to 42 years. Nonetheless, the highest incidence of bacterial meningitis remains among children younger than 2months of age, primarily because the pathogens responsible for meningitis in young infants differ from those causing infection in older children ${ }^{[7]}$. The present study was conducted to determine cases of bacterial meningitis in children.

We found that age group 1-4 years had 9 boys and 14 girls, 5-8 years had 7 boys and 6 girls and 8-12 years had 4 boys and 5 girls. Al-Aun et al. ${ }^{[8]}$ conducted a retrospective descriptive study on 50 children with the diagnosis of bacterial meningitis during 4 years period. The main cause of infection was streptococcus pneumoniae, followed by Haemophilus influenzae and Niesseria meningitides. Mortality was higher in infants and meningococcal infection, while complications were more encountered in cases of streptococcus pneumoniae. Cerebrospinal fluid culture was positive in 11 cases and Latex agglutination test in 39 .

We observed that common findings were fever in 42, vomiting in 36, rashes in 34 , drowsiness in 32 , headache in 20 , convulsions in 8 , nuchal rigidity in 5 and diarrhea in 12 . The causative organisms were Streptococcus pneumonia in 25 cases, hemophilic influenza type b in 12 and Neisseria Meningitides in 8 patients.

A lumbar puncture is necessary for the definitive diagnosis of bacterial meningitis. Analysis of CSF should include Gram stain and cultures, white blood cell (WBC) count and differential, and glucose and protein concentrations. Cytocentrifugation of the CSF enhances the ability to detect bacteria and perform a more accurate determination of the WBC differential. Typical findings in the CSF in bacterial meningitis include pleocytosis, usually with a WBC count greater than 1000 cells $/ \mathrm{mm} 3$ and predominance of polymorph nuclear leukocytes ${ }^{[9]}$.

Children with suspected meningitis sometimes receive oral or parenteral antibiotics before a lumbar puncture is performed. CSF cultures remain the reference standard for diagnosing bacterial meningitis, but antibiotic pretreatment decreases the likelihood of obtaining a positive CSF culture. In one study of 128 cases of pediatric meningitis, CSF cultures were negative in $29 \%$ of children who were pretreated with oral antibiotics and $44 \%$ of children who were pretreated with parenteral antibiotics ${ }^{[10]}$.

\section{Conclusion}

Authors found 45 cases of bacterial meningitis. The most common causative organisms was Streptococcus pneumonia.

\section{References}

1. Kneen R, Solomon T, Appleton R. The role of lumbar puncture in suspected CNS infection-A disappearing skill? Arch Dis Child. 2002; 87:181-3.

2. Schuchat A, Winger JD. Epidemiology of Bacterial Meningitis. Annals Nestle. 1997; 55:79-91.

3. Schlech WF, Ward J, Band JD et al. Bacterial Meningitis in the United States 1978 through 1981. JAMA. 1985; 253:1749-54.

4. Arditi M, Mason Jr EO, Bradley JS et al. Three-year multicenter surveillance of pneumococcal meningitis in children: clinical characteristics, and outcome related to penicillin susceptibility and dexamethasone use. Pediatrics. 1998; 102:1087-97.

5. Grimwood K, Anderson VA, Bond L et al. Adverse outcomes of bacterial meningitis in school age survivors. Pediatrics. 1995; 95:646-56.

6. Schrag S, Gorwitz R, Fultz-Butts K, Schuchat A. Prevention of perinatal group B streptococcal disease: revised guidelines from CDC. MMWR Morb Mortal 
Wkly Rep. 2002; 51:1-22.

7. Ashwal S, Parkin RM, Thompson JR et al. Bacterial meningitis in children: Current concepts of neurologic management. Adv Pediatr. 1993; 40:185-215.

8. Al-Aun M, AL-Aglouni SF, Hazza I, Ahmad M, Momani N. Bacterial meningitis in children. J Royal Med Services-Jordan 1994; 1:23-26.

9. Osrin D, Vergnano S, Costello A. Serious bacterial infections in newborn infants in developing countries. Curr Opin Infect Dis. 2004; 17:217-24.

10. Davidson KL, Rassy ME. The epidemiology of acute meningitis in children in England and Wales. Arch Dis Child. 2003; 88:662-664. 